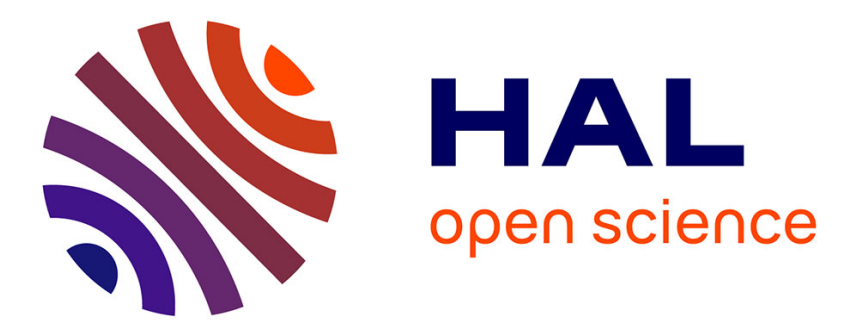

\title{
Translating the genetics of cystic fibrosis to personalized medicine
}

\author{
Harriet Corvol, Kristin E Thompson, Olivier Tabary, Philippe Le Rouzic, \\ Guillot Loïc
}

\section{- To cite this version:}

Harriet Corvol, Kristin E Thompson, Olivier Tabary, Philippe Le Rouzic, Guillot Loïc. Translating the genetics of cystic fibrosis to personalized medicine. Translational Research, The Journal of Laboratory and Clinical Medicine, 2015, 168, pp.40-49. 10.1016/j.trsl.2015.04.008 . hal-01148747

\section{HAL Id: hal-01148747 https: / hal.sorbonne-universite.fr/hal-01148747}

Submitted on 5 May 2015

HAL is a multi-disciplinary open access archive for the deposit and dissemination of scientific research documents, whether they are published or not. The documents may come from teaching and research institutions in France or abroad, or from public or private research centers.
L'archive ouverte pluridisciplinaire HAL, est destinée au dépôt et à la diffusion de documents scientifiques de niveau recherche, publiés ou non, émanant des établissements d'enseignement et de recherche français ou étrangers, des laboratoires publics ou privés. 


\section{Translating the Genetics of Cystic fibrosis to Personalized Medicine}

Harriet Corvol $^{1,2,3}$, Kristin E. Thompson ${ }^{1,2}$, Olivier Tabary ${ }^{1,2}$, Philippe le Rouzic ${ }^{1,2}$, Guillot $\operatorname{Loïc}^{1,2 *}$

${ }^{1}$ INSERM, UMR_S 938, CDR Saint-Antoine, Paris, France ; ${ }^{2}$ Sorbonne Universités, UPMC Univ Paris 06, UMR_S 938, CDR Saint-Antoine, Paris, France ; ${ }^{3}$ Pneumologie pédiatrique, APHP, Hôpital Trousseau, Paris, France ;

*Corresponding author: L. Guillot, Inserm UMR_S 938, CDR Saint Antoine, Inserm, Bât. Kourilsky $2^{\text {ème }}$ Étage, 34 Rue Crozatier, 75012 Paris, France. Tel.:+33 149284 682. E-mail: loic.guillot@ inserm.fr

\section{Abstract}

Cystic fibrosis (CF) is the most common life-threatening recessive genetic disease in the Caucasian population. This multi-organ disease is caused by mutations in the gene encoding the Cystic Fibrosis Transmembrane conductance Regulator (CFTR) protein, a chloride channel recognized as regulating several apical ion channels. The gene mutations result either in the lack of the protein at the apical surface, or in an improperly functioning protein. Morbidity and mortality due to the mutation of CFTR are mainly attributable to lung disease resulting from chronic infection/inflammation. Since its discovery as the causative gene in 1989, much progress has been achieved not only in clinical genetics but also in basic science studies. Recently, combinations of these efforts have been successfully translated into development and availability for patients of new therapies targeting specific CFTR mutations to correct the CFTR at the protein level. Current technologies such as Next Gene Sequencing (NGS) and novel genomic editing tools may offer new strategies to identify new CFTR variants and modifier genes, and to correct CFTR to pursue personalized medicine, which is already developed in some patient subsets. Personalized medicine, or P4 medicine for Personalized, "Predictive", "Preventive" and 'Participatory", is currently booming for 
cystic fibrosis. The various current and future challenges of personalized medicine as they apply to the issues faced in cystic fibrosis are discussed in this review. 


\section{Introduction}

Cystic fibrosis (CF) is the most common life-threatening recessive genetic disease in the Caucasian population, affecting approximately 70,000 individuals worldwide. This genetic disorder, caused by a mutation of the Cystic Fibrosis Transmembrane conductance Regulator $(C F T R)$ gene, is mostly characterized by recurrent lower respiratory infections, exocrine pancreatic insufficiency ( $85 \%$ of patients), and increased electrolyte concentration in sweat. A subset of patients also presents with a variety of symptoms which less commonly result in a

$\mathrm{CF}$ diagnosis, such as meconium ileus, liver disease and pancreatitis (1). Additional CF complications may also be observed in these patients, such as $\mathrm{CF}$ related diabetes. When $\mathrm{CF}$ was initially described in the 1930's, the patients only survived for a few months or years. While still associated with fatality, the median predicted life expectancy in $\mathrm{CF}$ has dramatically increased to around 40 years of age. However, analysis of demographic data of the European CF population highlights disease outcome disparities within Europe (2). This improvement of CF survival within specific European populations is multifactorial, including better diagnosis, phenotype characterization and treatment (e.g. antibiotics). To extend the survival and quality of life for CF patients, specific therapies targeting CFTR have been developed highlighting the translational research pipeline from basic science to clinical trials (3).

These specific therapies have directly affected the current progress in cystic fibrosis of the use of P4 medicine (for 'Personalized', 'Predictive', 'Preventive" and 'Participatory'). Medicine is per se "Personalized', i.e. individualized. Indeed, the best healthcare for each patient is chosen depending on his or her pathology and overall environment (allergic, psychological, socioeconomic). The concept of personalized medicine was developed in the 1990's by the pharmaceutical company Roche ${ }^{\circledR}$, in regards to the fact 
that one specific drug can induce various reactions in different individuals; and, for one individual, some drugs are highly effective whereas others are ineffective. Thus, anticipating which drug will be effective in one patient versus another is the basis for personalized medicine. This concept has been extended to the "4P medicine" which takes into account the patient as a whole (4) with:

- 'Personalized medicine", founded on how the individual genetic background could guide each patient's healthcare.

- "Predictive medicine", that allows the physician to assess the risk for one person to develop a disease or a disease's complication, leading to consider an individualized strategy to avoid disease appearance and/or progression.

- "Preventive medicine", that promotes a proactive approach, allowing to switch from a curative approach to a method based on the overall state of health and well-being.

- "Participative medicine", that allows the patient to take informed decisions and to be responsible for his own health.

This concept, well known and described in cancer care, is relevant to almost all other diseases, and particularly for genetic diseases, for which large scale genomics studies have been performed, such as CF (5).

\section{CFTR}

CFTR (OMIM: 602421) was identified in 1989 as the abnormal gene for CF (6-8). It is located on chromosome 7 (7q31.2), composed of 27 exons, and encodes for a protein, an ion channel that belongs to the ATP-binding cassette (ABC) transporter family of proteins. Consistent with the ABC transporters, the CFTR structure has 2 transmembrane domains (TMDs), and 2 nucleotide-binding domains (NBDs), but uniquely possesses a regulatory 
domain (R) (9). CFTR has several functions acting primarily as a chloride channel and regulating several other apical ion channels.

To date, almost 2,000 mutations have been identified and collected from the international CF genetics research community (http://www.genet.sickkids.on.ca/app; http://www.cftr2.org) (10). CFTR mutations have been found mostly in European-derived populations, and, with much less frequency, in African and East Asian populations (11). Missense mutations are the most prevalent (40\%), compared to frame shift (16\%), Splicing $(12 \%)$ and non-sense mutations $(8 \%)(11,12)$. The most common mutation (70\% of patients) is a three base deletion (c.1521_1523delCTT; Refseq transcript ID: NM_000492.3) that induces a deletion of a phenylalanine in position 508 (p.phe508del (p.F508del); Refseq protein ID NP_000483.3).

CFTR mutations are classified into five classes (sometimes six), according to their resulting damaging effect on the protein (reviewed in (13)) (Table 1). These classes are not exclusive, given that one mutation could have both a defective channel regulation ("class III") and a defective channel conduction ("class IV"), such as the c.350G>A/p.Arg117His (formerly R117H) mutation. 


\begin{tabular}{|c|c|c|c|c|}
\hline $\begin{array}{l}\text { I } \\
\text { Defective protein } \\
\text { production }\end{array}$ & $\begin{array}{c}\text { II } \\
\text { Defective protein } \\
\text { processing }\end{array}$ & $\begin{array}{c}\text { III } \\
\begin{array}{c}\text { Defective Channel } \\
\text { regulation }\end{array}\end{array}$ & $\begin{array}{c}\text { IV } \\
\text { Defective Channel } \\
\text { conduction }\end{array}$ & $\begin{array}{c}\text { V } \\
\text { Reduced protein } \\
\text { synthesis and function }\end{array}$ \\
\hline $\begin{array}{c}\text { c.1624G>T } \\
\text { p.Gly542X } \\
(\mathrm{G} 542 \mathrm{X}) \\
\mathbf{2 . 6 \%}\end{array}$ & $\begin{array}{c}\text { c.1521_1523del } \\
\text { p.Phe508del } \\
\text { (F508del) } \\
\mathbf{7 0 \%}\end{array}$ & $\begin{array}{c}\text { c.1652G>A } \\
\text { p.Gly551Asp } \\
\text { (G551D) } \\
\mathbf{2 \%}\end{array}$ & $\begin{array}{c}\text { c.350G>A } \\
\text { p.Arg117His } \\
\text { (R117H) } \\
\mathbf{1 . 1 4 \%}\end{array}$ & $\begin{array}{c}\text { c. } 2657+5 \mathrm{G}>\mathrm{A} \\
- \\
(2789+5 \mathrm{G}>\mathrm{A}) \\
\mathbf{0 . 7 6 \%}\end{array}$ \\
\hline $\begin{array}{c}\text { c.3846G>A } \\
\text { p.Trp1282X } \\
\text { (W1282X) } \\
\mathbf{1 . 4 9 \%}\end{array}$ & $\begin{array}{c}\text { c.3909C>G } \\
\text { p.Asn1303Lys } \\
(\mathrm{N} 1303 \mathrm{~K}) \\
\mathbf{1 . 7 5 \%}\end{array}$ & $\begin{array}{c}\text { c.1679G>C } \\
\text { p.Arg560Thr } \\
\text { (R560T) } \\
\mathbf{0 . 2 8 \%}\end{array}$ & $\begin{array}{c}\text { c.1040G>C } \\
\text { p.Arg347Pro } \\
\text { (R347P) } \\
\mathbf{0 . 3 3 \%}\end{array}$ & $\begin{array}{c}c .3717+12191 \mathrm{C}>\mathrm{T} \\
- \\
(3849+10 \mathrm{kbC}>\mathrm{T}) \\
\mathbf{0 . 7 4 \%}\end{array}$ \\
\hline $\begin{array}{c}c .489+1 \mathrm{G}>\mathrm{T} \\
- \\
(621+1 \mathrm{G}<\mathrm{T}) \\
\mathbf{1 . 1 5 \%}\end{array}$ & $\begin{array}{c}\text { c.1519_1521del } \\
\text { pIle507del } \\
\text { (I507del) } \\
\mathbf{0 . 4 5 \%}\end{array}$ & & $\begin{array}{c}\text { c. } 1000 \mathrm{C}>\mathrm{T} \\
\text { p.Arg334Trp } \\
\text { (R334W) } \\
\mathbf{0 . 2 4 \%}\end{array}$ & $\begin{array}{c}c .2988+1 \mathrm{G}>\mathrm{A} \\
- \\
(3120+1 \mathrm{G}>\mathrm{A}) \\
\mathbf{0 . 3 7 \%}\end{array}$ \\
\hline $\begin{array}{c}\text { c. } 1657 C>T \\
\text { p.Arg553X } \\
(\text { R553X) } \\
\mathbf{0 . 9 1 \%}\end{array}$ & $\begin{array}{c}\text { c. } 254 \mathrm{G}>\mathrm{A} \\
\text { p.Gly85Glu } \\
\text { (G85E) } \\
\mathbf{0 . 4 4 \%}\end{array}$ & & & $\begin{array}{c}\text { c.1364C>A } \\
\text { p.Ala455Glu } \\
(\mathrm{A} 455 \mathrm{E}) \\
\mathbf{0 . 3 \%}\end{array}$ \\
\hline $\begin{array}{c}\text { c. } 1585-1 \mathrm{G}<\mathrm{A} \\
- \\
(1717-1 \mathrm{G}<\mathrm{A}) \\
\mathbf{0 . 8 9 \%} \\
\end{array}$ & $\begin{array}{c}\text { c.2052delA } \\
\text { p.Lys684AsnfsX38 } \\
\text { (2184delA) } \\
\mathbf{0 . 1 6 \%} \\
\end{array}$ & & & \\
\hline $\begin{array}{c}\text { c. } 3484 C>T \\
\text { p.Arg1162X } \\
\text { (R1162X) } \\
\mathbf{0 . 4 8 \%}\end{array}$ & $\begin{array}{c}\text { c.3528delC } \\
\text { p.Lys1177serfsX15 } \\
\text { (3659delC) } \\
\mathbf{0 . 0 3 5 \%}\end{array}$ & & & \\
\hline $\begin{array}{c}c .579+1 \mathrm{G}>\mathrm{T} \\
- \\
(711+1 \mathrm{G}<\mathrm{T}) \\
\mathbf{0 . 2 3 \%} \\
\end{array}$ & & & & \\
\hline $\begin{array}{c}c .1766+1 \mathrm{G}>A \\
- \\
(1898+1 \mathrm{G}>\mathrm{A}) \\
\mathbf{0 . 3 4 \%}\end{array}$ & & & & \\
\hline
\end{tabular}

Table 1. CFTR mutation classes. Mutations are the classical American College Medical Genetics (ACMG) recommended panel of 23 classic CF-causing mutations for diagnosis. Names of variants followed HGVS nomenclature (c. denotes cDNA position, p., protein position) using reference transcript/protein (NM_000492.3/ NP_000483.3) sequence for CFTR respectively. Legacy names are in bracket. \% is the frequency of the mutation based on the CFTR2 database (February 2015).

CFTR sequence variants are usually named using two systems, either traditional, or recommended by the Human Genome Variation Society System (HGVS, www.hgvs.org/mutnomen/). One particular study highlighted the urgent need to move away from the traditional and historical naming towards the newer recommended HGVS nomenclature in order to standardize CFTR mutation screening results. The HGVS nomenclature (alone or in combination with the traditional one) for the common mutation c.1521_1523delCTT was only used by $20 \%$ of laboratories (14). Thus, it is now proposed that 
CFTR genetic reports should include both nomenclatures. A new database called 'CFTR2'" (Clinical and Functional Translation of CFTR; www.cftr2.org) has been recently created. This website is designed to provide information about specific CF mutations to patients and their family, clinicians, researchers, and the general public. It imparts information about the disease liability of a specific mutation when combined with another CF-causing mutation, and, furthermore, offers information regarding the sweat chloride levels, lung function, pancreatic status, and Pseudomonas aeruginosa infection rates in patients carrying these mutations and reported in the CFTR2 database.

New high throughput sequencing approaches will generate many genetic variations both in $\mathrm{CF}$ patients and in the general population. For $\mathrm{CF}$ and other monogenic diseases, annotating variants (i.e. assessing the disease liability of these rare variants) is a considerable challenge for the future (15). For CFTR, the disease liability has been validated and established for only a few dozen variants, in comparison to the almost 2,000 reported. In this context, a phenotypic-driven approach was used in the CFTR2 project to assess the disease liability of CFTR variants (10). This project has succeeded thanks to the cooperation of geneticists, clinicians and basic scientists. This strategy includes phenotypic and genomic data analyses, as well as biochemical measurements (Mean Sweat Chloride) and molecular biology studies (CFTR RNA and protein expression). Starting with 39,696 subjects, 159 variants were selected (seen at $\geq 0.01 \%$ in CFTR2). Finally, 127 variants have been assigned as "CF causing", 20 as "indeterminate", and 12 as "non-CF causing". Annotating these CFTR variants will benefit both clinical diagnosis and personalized therapies. In fact, the disease liability of the 23 mutations included in the AMCG testing panel $(16,17)$ (table 1) has been established for many years. However, the $85 \%$ sensitivity of this North-American panel left resulted in almost $30 \%$ of newborns with insufficient evidence to confirm the diagnosis of CF. Indeed, sensitivity of the mutation tests varies between populations. In non-Caucasian groups 
and Hispanic, the sensitivity is lower compared to Caucasians (18). In Europe, extensive heterogeneity in the distribution of CFTR is seen across the different European countries. Thus, best practices guidelines for CF molecular genetic diagnosis have been established, especially to take into account the regional disparities. Inclusion of the 127 disease-causing variants from CFTR2 increased the sensitivity for detection of CF alleles in white European individuals up to $95 \%$ (10). The non-Caucasian inventory of CFTR variants will be achieved due to the future CFTR2 recruitment that will include affected individuals from East Asia, Middle East, Africa and South-America (15).

The biological consequences (direct or indirect) of CFTR mutations are numerous and have been extensively studied, particularly for the p.F508del mutation. Not all the relevant publications can be included here. Briefly, the defective ion transport due to CFTR mutations results in reduced apical airway surface liquid (ASL), which leads to impaired mucociliary clearance that progressively induces obstruction of the airways with thickened mucus. This in turn creates a favorable environment for bacterial contamination and colonization. Interestingly, recent observations using a piglet model of $\mathrm{CF}$ suggest that mucociliary transport is a primary defect in CF (19). Patients with CF have an impaired host immune response especially against Pseudomonas aeruginosa, which is characterized by an exaggerated and ineffective airway inflammatory response. There is evidence suggesting that CFTR dysfunction affects innate immunity pathways, notably those associated with Toll Like Receptors (TLRs) (20) and that the initial predisposition to infection in infants with CF may represent a primary defect in local mucosal immunity (21). The temporal and causal interplay between infection and inflammation (chicken or egg) is still in debate. However, it has recently been shown that $c f t r^{-/-}$newborn piglets, a model which well reflects human CF lung disease, have an impaired host response without inflammation, suggesting that bacterial infection may initiate inflammation (22). 


\section{Lung modifiers}

Due to the intensive work on $C F T R$, the diversity of the clinical phenotype of lung disease among patients harboring the same genotype (e.g p.F508del homozygous) suggests that other environmental and genetic factors influence the clinical phenotype. Interestingly, discordant phenotypes are observed in CF siblings carrying the same CFTR mutations and sharing a similar environment, thusly supporting the need to search for CF modifier genes (23-29). To date the most studied respiratory phenotypes are lung function $\left(\mathrm{FEV}_{1}\right)$ decline and the susceptibility to Pseudomonas aeruginosa infection. This pathogen is known to be associated with a more rapid decline of the lung function and with increased mortality. Various strategies have been employed in order to discover these modifiers such as Genome Wide Association Studies (GWAS), candidate gene approaches, and, more recently, exome sequencing. These different strategies have identified many potential modifiers (reviewed in $(30,31))$. Briefly, the genes that have been mostly studied (replicated, large cohorts of patients) are the transforming growth factor beta 1 (TGFB1), mannose binding lectin 2 (MBL2), and the ancestral haplotype (AH) 8.1. TGF $\beta$ is a multifunctional protein involved in the regulation and the proliferation of numerous cell types. The most studied variants are in the promoter region (-509) and in codon 10 (2500 patients). Although some discrepancies exist between the various studies, an association has been observed with the variants inducing an increased expression of the protein (-509TT and codon 10CC) and the severity of the lung phenotype in CF patients $(32,33)$. MBL is an innate protein produced by the liver. During the acute inflammatory process, it accumulates in the lung and has a pivotal role in infectious diseases, specifically due to its binding properties to $\mathrm{CF}$ pathogens such as $P$. aeruginosa, $S$. aureus and B. cepacia. The haplotype in the first exon (A/O), known to modulate the serum level of MBL, has been investigated by several independent teams. A meta-analysis has shown that this haplotype, corresponding to a MBL deficiency, is associated with the severity 
of $\mathrm{CF}$ lung disease with an early acquisition of $P$. aeruginosa, more frequent airway colonization by B. cepacia, a decreased lung function in adults, more frequent transplantation needs and an increased mortality (34). The haplotype 8.1 AH is called ancestral as it is highly conserved. It is frequent in Caucasians (25\% in the general population) and is localized on the short arm of chromosome 6, in the coding region of the MHC (major histocompatibility complex). It includes major genes of the inflammatory response such as lymphotoxin a, Tumor Necrosis Factor (TNF), Heat Shock Protein A1B (HSPA1B) and RAGE (Receptor for Advanced Glycation Endproducts) (35). This haplotype has been shown to be associated with the severity of the lung disease in $404 \mathrm{CF}$ European patients; the 8.1 AH carriers having a faster $\mathrm{FEV}_{1}$ decline (36). Finally, a GWAS performed in a large CF cohort, of more than 3000 patients (37), has identified 7 regions associated with the respiratory phenotype near the genes APIP/EHF, AGTR2, HLA-DRA, EEA1, SLC8A3, AHRR and CDH8. The region around the $E H F$ and APIP genes, involved in apoptosis, was highly significant. Moreover, a linkage analysis in related patients showed another interesting region on chromosome 20q13.2, that remains to be fully studied.

Other phenotypes have been studied inorder to discover modifier genes and have been extensively reviewed elsewhere $(30,31)$.

Identification and characterization of these modifiers would allow a "predictive" and "preventive" medicine. Predictive medicine underlines the concept of the physician possessing the knowledge of the patient's whole genome in order to predict the onset of complications before they start. Preventive medicine may then be applied, and therapies may be provided prior to the onset of these complications. This would be a new area for the patients care, "proactive" rather than the current "reactive" care.

\section{Cystic fibrosis therapy}


New personalized therapies are under development, targeting either the dysfunctional gene or protein. This new era allows hoping for curative strategies in a very next future, whereas current treatments mostly focus on end-stage disease of the affected organs.

\section{Gene therapy}

Gene therapy would be the hoped for gold standard treatment for $\mathrm{CF}$ patients. Compared to CF protein therapy, gene therapy is expected to be broadly prescribable to $\mathrm{CF}$ patients, without restriction to a specific class of mutations. However, this strategy faces important challenges. The concept of gene therapy in CF consists of adding a correct sequence of CFTR in a way that it is incorporated into the patients' cells and is able to circumvent the CFTR mutation. An important step in creating this correct version of the gene is choosing a transporter. Two types of vectors are currently available, either synthetic or viral. The viruses studied for gene transfer are adenovirus, adeno associated virus (AAV), lentivirus and retrovirus. Inconveniently, these vectors induced an excessive inflammatory response or showed poor efficacy in CF patients (38). Thus, synthetic vectors that do not or weakly induce immunogenicity would be an interesting alternative. Currently, a phase III trial is ongoing in the UK with a synthetic lipidic vector. It will include 130 patients older than 12 years old, who will be given the normal gene by inhalation once a month for one year (39). Effects will be evaluated by recording the respiratory symptoms, the lung function $\left(\mathrm{FEV}_{1}\right)$, blood markers (inflammation and immunity) and sputum characteristics.

It is important to highlight that so far gene therapy agents have been delivered only to the lung, i.e. by inhalation, and would have no benefit for other organs. Moreover, another challenging issue is access to the site of delivery, as the thick respiratory mucus may prevent a good bioavailability. Chronic administration may also be problematic even with a low immunogenic system. 
New genome editing tools including zinc finger nucleases (ZFNs), transcription activator-like effector nucleases (TALENs), and RNA guide engineered nucleases derived from the bacterial clustered regulatory interspaced short palindromic repeat (CRISPR)-cas (CRISPR-associated) system associated with stem cell therapy offer attractive alternatives. Briefly, these nucleases cleave DNA at a specific site of interest and allow genome modifications of the gene (40). Compared to TALENs and ZNFs, the CRISPR/Cas9 system which requires short programmable gRNA for DNA targeting is cheap and easy to design and produce. However much work remains to be done, in particular enhancing the specificity to avoid deleterious off target effects and to further develop the delivery methods (41). In primary adult stem cells, intestinal cell organoids of CF patients, the CRISPR/Cas9 system was used to restore the CFTR locus and successfully restore CFTR function (organoid swelling) (42). Using an iPS (induced pluripotent stem cell) cell line homozygous for the p.F508del mutation, candidate TALENs were generated to correct the CFTR defect. Generation of mature airway epithelia with a functional CFTR from human embryonic stem cells have been recently realized (43). Also, in this study, CF-induced pluripotent stem cells (iPSCs)-derived from epithelial cells treated by the CFTR corrector compound C18, showed an increased amount of CFTR in the plasma membrane. This is promising for the future of a "personalized" regenerative medicine. In this context, iPSC-derived epithelial cells may be also used to test therapeutics in a patient-specific manner, taking into account the whole genome of a patient, especially the CFTR allelic heterogeneity and the modifier genes.

\section{Protein personalized Therapy}

Protein therapies are aimed at correcting the dysfunction of CFTR. As mentioned previously, many CFTR mutations alter the structure/function of the protein. In this context, various therapies have been developed targeting specific mutation classes, in order to 
personalize the treatment. Here, the different classes will be explained and the current strategies to correct the mutations within those classes will be discussed.

Class I mutations are nonsense, frameshift and splice mutations resulting in the absence or little expression of CFTR (Figure 1.). Nonsense mutations induce a premature termination codon (PTC) in the mRNA, which results in a premature stop of translation, and the absence of the protein. To correct this type of mutation, molecules that would promote readthrough of the PTCs and, thus, allow the production of functional CFTR, are needed. The first studies have tested antibiotics of the aminoglycoside family, as gentamycin $(44,45)$. The several clinical trials with gentamycin have indeed shown benefits in the CF patients, with a normalization of the chloride transport in the nasal epithelium (46-48). However, due to adverse drug-effects of long-term use of aminosides (nephrotoxicity and ototoxicity), a molecule without antibiotic properties was identified and developed by PTC Therapeutics ${ }^{\circledR}$ known as PTC124 or Ataluren $(49,50)$. Clinical trials with this molecule have shown better transport of chloride in the nasal epithelium, but no real clinical benefit (51-53). Additionally, the efficiency is variable among patients, mostly due to the causal CFTR mutation. In fact, patients with the p.Trp1282X (p.W1282X) were better responders than those carrying other class I mutations (53). In the last international phase III clinical trial, 238 patients older than 6 years of age were enrolled. Patients received Ataluren or placebo for 48 weeks (54). No significant respiratory benefits were observed for the whole cohort, either for the evolution of the percent-predicted $\mathrm{FEV}_{1}$, or for the numbers of exacerbations. However, in the subgroup of patients not chronically treated with inhaled aminosides, an increase of the percent-predicted $\mathrm{FEV}_{1}(+5,7 \%)$, and a reduction in the number of exacerbations were observed. In the Ataluren group, a significant increase of the creatinine was detected in comparison to patients treated with the placebo, without other adverse effects. The clinical benefit seems modest, and will be important to confirm in larger cohorts before approving this drug as a standard of care. Thus, 
an additional phase III international trial is underway, that excludes patients receiving chronic inhaled aminoglycosides (ClinicalTrials.gov, NCT02139306).

In class III mutations, CFTR is expressed at the cell surface but is non-functional. To correct this class of mutations, work is ongoing to identify molecules able to restore the CFTR chloride transport function at least partially, known as "'potentiators.' In this field, Vertex ${ }^{\circledR}$ Laboratories were pioneers. Highthrough-put screening methodology investigating more than 200,000 molecules identified a potentiator named Vertex 770 (VX-770, Ivacaftor). VX-770 was indeed able to potentiate the mutated CFTR protein, to increase the open probability of the chloride channel, to decrease the excessive absorption of sodium, and to restore the ciliary beat. This was initially demonstrated in the CFTR p.Gly551Asp (p.G551D) mutation, which is the most frequent class III mutation, occuring in $2 \%$ (heterozygous) of CF patients worldwide (55). The clinical trial leading to commercialization was a phase III study (Strive ${ }^{\circledR}$ study) including 84 patients treated, against 83 with placebo, older than 12 years old and carrying at least one p.G551D CFTR allele (56). Significant clinical benefits have been shown both for respiratory status $\left(10 \%\right.$ of increase for the percent-predicted $\mathrm{FEV}_{1}$ with a decrease of the number of exacerbations), and for the general status (gain of weight, quality of life). A significant decrease in the sweat chloride levels was also demonstrated. The extended clinical study (Envision ${ }^{\circledR}$, children between 6-11 years old) showed similar improvements (57). Consequently, in 2012, Ivacaftor was approved in the US and in Europe by the Food and Drug Administration (FDA) and the European Medical Agency (EMA) respectively, and commercialized under the name of Kalydeco ${ }^{\circledR}$ for patients older than 6 years old, and with at least one p.G551D CFTR allele. Further, Kalydeco ${ }^{\circledR}$ has been tested in patients carrying other class III mutations, or targeted class IV and V mutations (sharing functional similarities with the class III) (58). The new trials led to an extension of the FDA and EMA approval to 8 additional gating mutations: p.Gly178Arg (p.G178R), p.Ser549Asn (p.S549N), p.Ser549Arg 
(p.S549R), p.Gly551Ser (p.G551S), p.Gly1244Glu (p.G1244E), p.Ser1251Asn (p.S1251N), p.Ser1255Pro (pS1255P) and p.Gly1349Asp (p.G1349D) (59). Recently, Ivacaftor has also been shown to benefit patients carrying the c.350G>A/p.Arg117His (formerly R117H) mutation, that is relatively common in the CF population, and leads to both defective channel regulation (sharing similarities with the class III mutations) and conduction. Thus, the FDA also approved Ivacaftor as a treatment for CF subjects aged greater than 6 years old with at least one copy of $R 117 H-C F T R$ (60). Additionally, Ivacaftor is currently being tested in patients carrying non-R117H residual function mutations. The phase II clinical trial showed encouraging results with improvement of lung function and a decreased sweat chloride level; a phase III clinical trial will surely be planned shortly (Vertex release 852372).

As introduced above, the p.Phe508del (p.F508del) mutation is the most common class II mutation. Worldwide, $70 \%$ of the CF patients carry at least one p.F508del CFTR allele, and $50 \%$ are homozygotes for this mutation. It results in the misfolding of the protein leading to rapid degradation of the protein in the cell, preventing its expression at the cell surface. Molecules that could prevent this degradation are called "correctors", and would allow CFTR to be sufficiently expressed at the cell surface. Vertex developed the VX-809 (or Lumacaftor), a corrector which may achieve this goal. In fact, using bronchial epithelial cells harboring the p.F508del homozygous mutation, VX-809 increased the chloride transport $(55-58,61)$. A phase II clinical trial has shown a modest beneficial effect on the sweat chloride levels in patients homozygous for the p.F508del mutation (62). This suggested that merely restoring CFTR expression was not sufficient, and that the function of CFTR had to be promoted by a potentiator. Consequently, a phase II trial in adults homozygous or heterozygous for the p.F508del mutation was realized using the combination of Ivacaftor and Lumafactor. This association was well tolerated, and, in the homozygous p.F508del patients, improved lung function (gain of $8.6 \%$ percent-predicted $\mathrm{FEV}_{1}$ ), and significantly decreased the sweat 
chloride level (63). However, no $\mathrm{FEV}_{1}$ improvement was observed for the p.F508del heterozygous patients. Two international phase III studies encompassing 1100 patients homozygous for p.F508del ended this year, and promising results have been shown at the last North-American CF Conference (NACFC 2014, Atlanta) but are unpublished as of yet (Vertex press release) $(64,65)$. Interestingly, another promising compound similar to Lumacaftor, VX-661, has also been developed by Vertex, and clinical trials are underway. Interim results of a phase II, double-blind, placebo-controlled study of VX-661 (various daily doses) alone or in combination with Ivacaftor have been reported for p.F508del homozygous patients (66). The treatment was well tolerated and led to an improvement of the percentpredicted $\mathrm{FEV}_{1}$ (maximum $9 \%$ of gain with a combination VX-661 and Ivacaftor), and a decreased sweat chloride level.

Although the efficacy of Ivacaftor has been proven, the question of the costeffectiveness, i.e. affordability compared to long-term benefit of this personalized treatment, for life, must be taken into account and is debatable $(67,68)$. This drug is indeed highly expensive (around 311,000 US \$/year) and the actual knowledge of its efficacy would support a long-term (all life-long) prescription. However, to corroborate that the benefits seen in the clinical trials are indeed sustained long-term, a prospective follow-up of the treated patients should be realized and reported. Then, if the long-term benefit is ascertained, as a society, we would be both ethically and morally obliged to assure the access to these personalized therapies for all CF patients that would benefit.

\section{Pharmacogenomics}

Even if specific $\mathrm{CF}$ protein therapies are emerging, inter-individual variation to drug treatment is unfortunately expected and has to be considered in relation to the $4 \mathrm{P}$ medicine. In this context, the future upsurge of highthrough-put genomic data concerning 
pharmacogenomics in CF may contribute to the development of personalized treatment across specific subgroups of CF patients. Importantly, Kalydeco ${ }^{\circledR}$ is mainly metabolized by the cytochrome P450 family 3, subfamily A (CYP3A) and early in its development, Kalydeco ${ }^{\circledR}$ and metabolites have been shown to be able to inhibit CYP3A, and other cytochromes (CYP2C8, CY2C9 and CYP2D6). A recent drug-drug interaction (DDI) study examined the effect of Kalydeco ${ }^{\circledR}$ on sensitive substrates of CYP2C8 (rosiglitazone), CYP3A (midazolam), CYP2D6 (desipramine), and P-glycoprotein (P-gp) (digoxin). Also, a DDI study of Kalydeco ${ }^{\circledR}$ combined with oral contraceptives was realized that indicated that there was no need for dose adjustment. Kalydeco ${ }^{\circledR}$ is a weak inhibitor of CYP3A and P-gp, but has no effect on CYP2C8 and CYP2D6 (69). Thus, caution must be exercised with co-administration of CYP2C9, CYP3A, and/or Pgp substrates. Although CYP SNPs may affect the level of enzyme production, to date, no genomic studies have been performed to assess the effect of CYP variants on the pharmacokinetics of Kalydeco ${ }^{\circledR}$ in CF patients. Interestingly, CYP3A also interacts with widely used drugs for CF patients, such as macrolides such as azithromycin (70) or Tacrolimus (71). A recent study has shown that Tacrolimus clearance was $40 \%$ faster in CYP3A5 expressers compared to non-expressers. Pharmacogenetics testing is a growing current and future challenge that would be predictive for efficacy and for adverse drugs effects.

\section{Conclusion}

35 years following the discovery of $C F T R$, personalized medicine is not merely just a concept for the treatment of cystic fibrosis but a reality for the patients. Protein specific therapy is a clear step-ahead in terms of therapeutic options for CF patients, particularly in regards to the new correctors, potentiators and readthrough drugs. Finally, the highthroughput genomic data, new genome editing tools, and stem cell regenerative medicine are exciting 
and will hopefully further evolve into new affordable therapeutics and rise to meet the needs of CF patients.

\section{Acknowledgements}

LG received a research grant from the French cystic-fibrosis nonprofit organization Vaincre la Mucoviscidose. KT received a postdoc fellow grant from the French cystic-fibrosis nonprofit organization Vaincre la Mucoviscidose. All authors have read the journal's policy on conflicts of interest, have no conflict of interest to declare and have read the journal's authorship agreement. The manuscript has been reviewed by and approved by all named authors.

\section{Figure legends}

Figure 1. CFTR mutations classes (I to V), their functional consequences and their potential specific therapies. CFTR is composed of 2 nucleotide-binding domains (NBD1 and NBD2), two transmembrane domains (TMD1 and TMD2) and one regulatory (R) domain.

\section{References}

1. Robinson P. Cystic fibrosis. Thorax. 2001;56(3):237-41.

2. McCormick J, Mehta G, Olesen HV, Viviani L, Macek M, Jr., Mehta A, et al. Comparative demographics of the European cystic fibrosis population: a cross-sectional database analysis. Lancet. 2010;375(9719):1007-13.

3. Chignard $M$, Ramphal R. Basic research funding by philanthropic organizations: a case in point. Am J Respir Crit Care Med. 2013;188(11):1376-8.

4. Weston AD, Hood L. Systems biology, proteomics, and the future of health care: toward predictive, preventative, and personalized medicine. J Proteome Res. 2004;3(2):179-96.

5. Bauer DC, Gaff C, Dinger ME, Caramins M, Buske FA, Fenech M, et al. Genomics and personalised whole-of-life healthcare. Trends Mol Med. 2014;20(9):479-86.

6. Riordan JR, Rommens JM, Kerem B, Alon N, Rozmahel R, Grzelczak Z, et al. Identification of the cystic fibrosis gene: cloning and characterization of complementary DNA. Science. 1989;245(4922):1066-73.

7. Rommens JM, lannuzzi MC, Kerem B, Drumm ML, Melmer G, Dean M, et al. Identification of the cystic fibrosis gene: chromosome walking and jumping. Science. 1989;245(4922):1059-65.

8. Kerem B, Rommens JM, Buchanan JA, Markiewicz D, Cox TK, Chakravarti A, et al. Identification of the cystic fibrosis gene: genetic analysis. Science. 1989;245(4922):1073-80.

9. Cant N, Pollock N, Ford RC. CFTR structure and cystic fibrosis. Int J Biochem Cell Biol. 2014;52:15-25.

10. Sosnay PR, Siklosi KR, Van Goor F, Kaniecki K, Yu H, Sharma N, et al. Defining the disease liability of variants in the cystic fibrosis transmembrane conductance regulator gene. Nat Genet. 2013;45(10):1160-7. 
11. Castellani C, Cuppens H, Macek M, Jr., Cassiman JJ, Kerem E, Durie P, et al. Consensus on the use and interpretation of cystic fibrosis mutation analysis in clinical practice. J Cyst Fibros. 2008;7(3):179-96.

12. Ferec C, Scotet V, Beucher J, Corvol H. [Genetics and modifier genes, atypical and rare forms]. Arch Pediatr. 2012;19 Suppl 1:S3-7.

13. Fanen P, Wohlhuter-Haddad A, Hinzpeter A. Genetics of cystic fibrosis: CFTR mutation classifications toward genotype-based CF therapies. Int J Biochem Cell Biol. 2014;52:94-102.

14. Berwouts S, Morris MA, Girodon E, Schwarz M, Stuhrmann M, Dequeker E. Mutation nomenclature in practice: findings and recommendations from the cystic fibrosis external quality assessment scheme. Hum Mutat. 2011;32(11):1197-203.

15. Cutting GR. Cystic fibrosis genetics: from molecular understanding to clinical application. Nature reviews Genetics. 2014.

16. Grody WW, Cutting GR, Klinger KW, Richards CS, Watson MS, Desnick RJ, et al. Laboratory standards and guidelines for population-based cystic fibrosis carrier screening. Genetics in medicine : official journal of the American College of Medical Genetics. 2001;3(2):149-54.

17. Watson MS, Cutting GR, Desnick RJ, Driscoll DA, Klinger K, Mennuti M, et al. Cystic fibrosis population carrier screening: 2004 revision of American College of Medical Genetics mutation panel. Genetics in medicine : official journal of the American College of Medical Genetics. 2004;6(5):387-91. 18. Palomaki GE, FitzSimmons SC, Haddow JE. Clinical sensitivity of prenatal screening for cystic fibrosis via CFTR carrier testing in a United States panethnic population. Genetics in medicine : official journal of the American College of Medical Genetics. 2004;6(5):405-14.

19. Hoegger MJ, Fischer AJ, McMenimen JD, Ostedgaard LS, Tucker AJ, Awadalla MA, et al. Cystic fibrosis. Impaired mucus detachment disrupts mucociliary transport in a piglet model of cystic fibrosis. Science. 2014;345(6198):818-22.

20. Sallenave JM. Phagocytic and signaling innate immune receptors: are they dysregulated in cystic fibrosis in the fight against Pseudomonas aeruginosa? Int J Biochem Cell Biol. 2014;52:103-7.

21. Cohen TS, Prince A. Cystic fibrosis: a mucosal immunodeficiency syndrome. Nat Med. 2012;18(4):509-19.

22. Stoltz DA, Meyerholz DK, Pezzulo AA, Ramachandran S, Rogan MP, Davis GJ, et al. Cystic fibrosis pigs develop lung disease and exhibit defective bacterial eradication at birth. Sci Transl Med. 2010;2(29):29ra31.

23. Bronsveld I, Bijman J, Mekus F, Ballmann M, Veeze HJ, Tummler B. Clinical presentation of exclusive cystic fibrosis lung disease. Thorax. 1999;54(3):278-81.

24. Bronsveld I, Mekus F, Bijman J, Ballmann M, de Jonge HR, Laabs U, et al. Chloride conductance and genetic background modulate the cystic fibrosis phenotype of Delta F508 homozygous twins and siblings. J Clin Invest. 2001;108(11):1705-15.

25. Bronsveld I, Mekus F, Bijman J, Ballmann M, Greipel J, Hundrieser J, et al. Residual chloride secretion in intestinal tissue of deltaF508 homozygous twins and siblings with cystic fibrosis. The European CF Twin and Sibling Study Consortium. Gastroenterology. 2000;119(1):32-40.

26. Mekus F, Ballmann M, Bronsveld I, Bijman J, Veeze H, Tummler B. Categories of deltaF508 homozygous cystic fibrosis twin and sibling pairs with distinct phenotypic characteristics. Twin Res. 2000;3(4):277-93.

27. Mekus F, Ballmann M, Bronsveld I, Dork T, Bijman J, Tummler B, et al. Cystic-fibrosis-like disease unrelated to the cystic fibrosis transmembrane conductance regulator. Hum Genet. 1998;102(5):582-6.

28. Mekus F, Laabs $U$, Veeze $H$, Tummler B. Genes in the vicinity of CFTR modulate the cystic fibrosis phenotype in highly concordant or discordant F508del homozygous sib pairs. Hum Genet. 2003;112(1):1-11.

29. Cutting GR. Modifier genes in Mendelian disorders: the example of cystic fibrosis. Ann N Y Acad Sci. 2010;1214:57-69.

30. Guillot L, Beucher J, Tabary O, Le Rouzic P, Clement A, Corvol H. Lung disease modifier genes in cystic fibrosis. Int J Biochem Cell Biol. 2014;52:83-93. 
31. Weiler CA, Drumm ML. Genetic influences on cystic fibrosis lung disease severity. Front Pharmacol. 2013;4:40.

32. Corvol H, Boelle PY, Brouard J, Knauer N, Chadelat K, Henrion-Caude A, et al. Genetic variations in inflammatory mediators influence lung disease progression in cystic fibrosis. Pediatr Pulmonol. 2008;43(12):1224-32.

33. Drumm ML, Konstan MW, Schluchter MD, Handler A, Pace R, Zou F, et al. Genetic modifiers of lung disease in cystic fibrosis. N Engl J Med. 2005;353(14):1443-53.

34. Chalmers JD, Fleming GB, Hill AT, Kilpatrick DC. Impact of mannose-binding lectin insufficiency on the course of cystic fibrosis: A review and meta-analysis. Glycobiology. 2011;21(3):271-82.

35. Beucher J, Boelle PY, Busson PF, Muselet-Charlier C, Clement A, Corvol H. AGER -429T/C is associated with an increased lung disease severity in cystic fibrosis. PLoS One. 2012;7(7):e41913. 36. Corvol H, Beucher J, Boelle PY, Busson PF, Muselet-Charlier C, Clement A, et al. Ancestral haplotype 8.1 and lung disease severity in European cystic fibrosis patients. J Cyst Fibros. 2012;11(1):63-7.

37. Wright FA, Strug LJ, Doshi VK, Commander CW, Blackman SM, Sun L, et al. Genome-wide association and linkage identify modifier loci of lung disease severity in cystic fibrosis at $11 \mathrm{p} 13$ and 20q13.2. Nat Genet. 2011;43(6):539-46.

38. Griesenbach U, Alton EW. Moving forward: cystic fibrosis gene therapy. Hum Mol Genet. 2013;22(R1):R52-8.

39. Alton EW, Boyd AC, Cheng SH, Cunningham S, Davies JC, Gill DR, et al. A randomised, doubleblind, placebo-controlled phase IIB clinical trial of repeated application of gene therapy in patients with cystic fibrosis. Thorax. 2013;68(11):1075-7.

40. $\quad \operatorname{Kim~H}, \mathrm{Kim} J \mathrm{~S}$. A guide to genome engineering with programmable nucleases. Nature reviews Genetics. 2014;15(5):321-34.

41. Zhang F, Wen Y, Guo X. CRISPR/Cas9 for genome editing: progress, implications and challenges. Hum Mol Genet. 2014;23(R1):R40-R6.

42. Schwank G, Koo BK, Sasselli V, Dekkers JF, Heo I, Demircan T, et al. Functional repair of CFTR by CRISPR/Cas9 in intestinal stem cell organoids of cystic fibrosis patients. Cell Stem Cell. 2013;13(6):653-8.

43. Wong AP, Bear CE, Chin S, Pasceri P, Thompson TO, Huan LJ, et al. Directed differentiation of human pluripotent stem cells into mature airway epithelia expressing functional CFTR protein. Nat Biotechnol. 2012;30(9):876-82.

44. Du M, Jones JR, Lanier J, Keeling KM, Lindsey JR, Tousson A, et al. Aminoglycoside suppression of a premature stop mutation in a Cftr-/- mouse carrying a human CFTR-G542X transgene. J Mol Med (Berl). 2002;80(9):595-604.

45. Sermet-Gaudelus I, Renouil M, Fajac A, Bidou L, Parbaille B, Pierrot S, et al. In vitro prediction of stop-codon suppression by intravenous gentamicin in patients with cystic fibrosis: a pilot study. BMC Med. 2007;5:5.

46. Clancy JP, Bebok Z, Ruiz F, King C, Jones J, Walker L, et al. Evidence that systemic gentamicin suppresses premature stop mutations in patients with cystic fibrosis. Am J Respir Crit Care Med. 2001;163(7):1683-92.

47. Wilschanski M, Famini C, Blau H, Rivlin J, Augarten A, Avital A, et al. A pilot study of the effect of gentamicin on nasal potential difference measurements in cystic fibrosis patients carrying stop mutations. Am J Respir Crit Care Med. 2000;161(3 Pt 1):860-5.

48. Wilschanski M, Yahav Y, Yaacov Y, Blau H, Bentur L, Rivlin J, et al. Gentamicin-induced correction of CFTR function in patients with cystic fibrosis and CFTR stop mutations. N Engl J Med. 2003;349(15):1433-41.

49. Du M, Liu X, Welch EM, Hirawat S, Peltz SW, Bedwell DM. PTC124 is an orally bioavailable compound that promotes suppression of the human CFTR-G542X nonsense allele in a CF mouse model. Proc Natl Acad Sci U S A. 2008;105(6):2064-9. 
50. Hirawat S, Welch EM, Elfring GL, Northcutt VJ, Paushkin S, Hwang S, et al. Safety, tolerability, and pharmacokinetics of PTC124, a nonaminoglycoside nonsense mutation suppressor, following single- and multiple-dose administration to healthy male and female adult volunteers. J Clin Pharmacol. 2007;47(4):430-44.

51. Kerem E, Hirawat S, Armoni S, Yaakov Y, Shoseyov D, Cohen M, et al. Effectiveness of PTC124 treatment of cystic fibrosis caused by nonsense mutations: a prospective phase II trial. Lancet. 2008;372(9640):719-27.

52. Sermet-Gaudelus I, Boeck KD, Casimir GJ, Vermeulen F, Leal T, Mogenet A, et al. Ataluren (PTC124) induces cystic fibrosis transmembrane conductance regulator protein expression and activity in children with nonsense mutation cystic fibrosis. Am J Respir Crit Care Med.

2010;182(10):1262-72.

53. Wilschanski M, Miller LL, Shoseyov D, Blau H, Rivlin J, Aviram M, et al. Chronic ataluren (PTC124) treatment of nonsense mutation cystic fibrosis. Eur Respir J. 2011;38(1):59-69.

54. Kerem E, Konstan MW, De Boeck K, Accurso FJ, Sermet-Gaudelus I, Wilschanski M, et al. Ataluren for the treatment of nonsense-mutation cystic fibrosis: a randomised, double-blind, placebo-controlled phase 3 trial. Lancet Respir Med. 2014;2(7):539-47.

55. Van Goor F, Hadida S, Grootenhuis PD, Burton B, Cao D, Neuberger T, et al. Rescue of CF airway epithelial cell function in vitro by a CFTR potentiator, VX-770. Proc Natl Acad Sci U S A. 2009;106(44):18825-30.

56. Ramsey BW, Davies J, McElvaney NG, Tullis E, Bell SC, Drevinek P, et al. A CFTR potentiator in patients with cystic fibrosis and the G551D mutation. N Engl J Med. 2011;365(18):1663-72.

57. Davies JC, Wainwright CE, Canny GJ, Chilvers MA, Howenstine MS, Munck A, et al. Efficacy and safety of ivacaftor in patients aged 6 to 11 years with cystic fibrosis with a G551D mutation. Am J Respir Crit Care Med. 2013;187(11):1219-25.

58. Yu H, Burton B, Huang CJ, Worley J, Cao D, Johnson JP, Jr., et al. Ivacaftor potentiation of multiple CFTR channels with gating mutations. Journal of cystic fibrosis : official journal of the European Cystic Fibrosis Society. 2012;11(3):237-45.

59. De Boeck K, Munck A, Walker S, Faro A, Hiatt P, Gilmartin G, et al. Efficacy and safety of ivacaftor in patients with cystic fibrosis and a non-G551D gating mutation. Journal of cystic fibrosis : official journal of the European Cystic Fibrosis Society. 2014.

60. Carter S, Kelly S, Caples E, Grogan B, Doyle J, Gallagher CG, et al. Ivacaftor as salvage therapy in a patient with cystic fibrosis genotype F508del/R117H/IVS8-5T. J Cyst Fibros. 2015.

61. Van Goor F, Hadida S, Grootenhuis PD, Burton B, Stack JH, Straley KS, et al. Correction of the F508del-CFTR protein processing defect in vitro by the investigational drug VX-809. Proc Natl Acad Sci U S A. 2011;108(46):18843-8.

62. Clancy JP, Rowe SM, Accurso FJ, Aitken ML, Amin RS, Ashlock MA, et al. Results of a phase lla study of VX-809, an investigational CFTR corrector compound, in subjects with cystic fibrosis homozygous for the F508del-CFTR mutation. Thorax. 2012;67(1):12-8.

63. Boyle MP, Bell SC, Konstan MW, McColley SA, Rowe SM, Rietschel E, et al. A CFTR corrector (lumacaftor) and a CFTR potentiator (ivacaftor) for treatment of patients with cystic fibrosis who have a phe508del CFTR mutation: a phase 2 randomised controlled trial. Lancet Respir Med. 2014;2(7):527-38.

64. Rosenfeld M, Marigowda G, Liu F, Waltz D. EFFECT OF LUMACAFTOR IN COMBINATION WITH IVACAFTOR ON FEV1 AND SAFETY MEASURES IN PATIENTS AGED 6-11 YEARS WITH CF WHO ARE HOMOZYGOUS FOR F508DEL-CFTR. Pediatric Pulmonology. 2014;49:287-.

65. Elborn J, Wainwright CE, Ramsey B, Huang X, Marigowda G, Waltz D, et al. EFFECT OF LUMACAFTOR IN COMBINATION WITH IVACAFTOR IN PATIENTS WITH CYSTIC FIBROSIS WHO ARE HOMOZYGOUS FOR F508DEL-CFTR: THE TRAFFIC STUDY. Pediatric Pulmonology. 2014;49:304-5. 66. Donaldson S, Pilewski J, Griese M, Dong Q, Lee PS. WS7.3 VX-661, an investigational CFTR corrector, in combination with ivacaftor, a CFTR potentiator, in patients with CF and homozygous for the F508Del-CFTR mutation: Interim analysis. Journal of Cystic Fibrosis.12:S14. 
67. Balfour-Lynn IM. Personalised medicine in cystic fibrosis is unaffordable. Paediatric respiratory reviews. 2014;15 Suppl 1:2-5.

68. Bilton D. Personalised medicine in cystic fibrosis must be made affordable. Paediatric respiratory reviews. 2014;15 Suppl 1:6-7.

69. Robertson SM, Luo X, Dubey N, Li C, Chavan AB, Gilmartin GS, et al. Clinical drug-drug interaction assessment of ivacaftor as a potential inhibitor of cytochrome P450 and P-glycoprotein. J Clin Pharmacol. 2014.

70. Westphal JF. Macrolide - induced clinically relevant drug interactions with cytochrome P450A (CYP) 3A4: an update focused on clarithromycin, azithromycin and dirithromycin. Br J Clin Pharmacol. 2000;50(4):285-95.

71. Monchaud C, de Winter BC, Knoop C, Estenne M, Reynaud-Gaubert M, Pison C, et al. Population pharmacokinetic modelling and design of a Bayesian estimator for therapeutic drug monitoring of tacrolimus in lung transplantation. Clinical pharmacokinetics. 2012;51(3):175-86. 

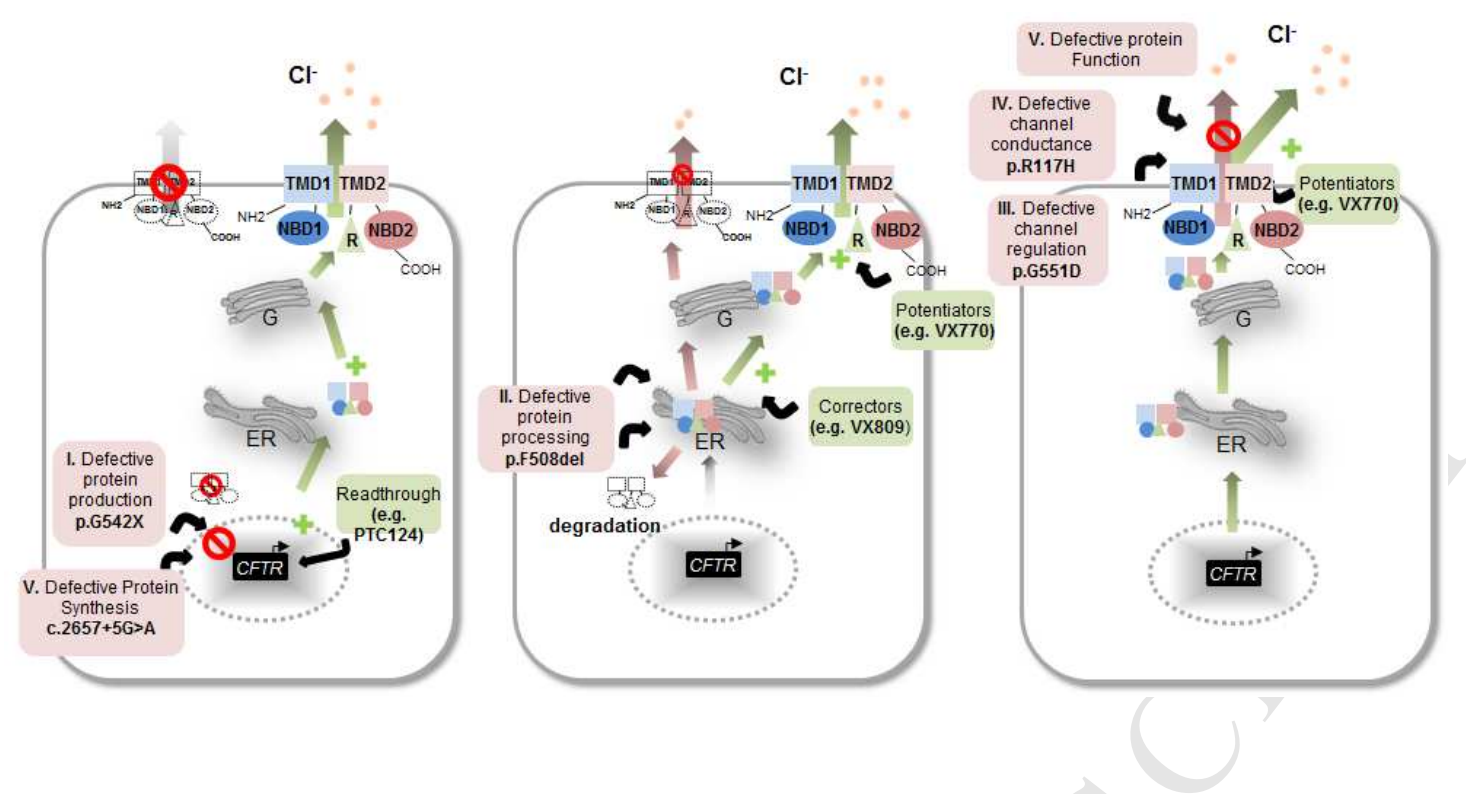